\title{
Adorno, Debord ve Baudrillard'da Kültür ve Sanat
}

\author{
Yrd. Doç. Engin Ümer
}

Makale Geliș Tarihi: 15.04.2016

Yayına Kabul Tarihi: 13.06.2016

\section{$\ddot{O} z$}

Theodor Adorno, kültür endüstrisi düşüncesinde sanatı 'sığınak' olarak görmüş, sanatın kitle kültürünün etkilerini azaltma ve onun işleyişinin dışında kalması gerektiğini önermiştir. Guy Debord, "gösteri toplumu" düşüncesiyle her şeyin bir gösteriye dönüştügüünü ve sanatsal ifadenin kişisel bir deneyim olarak insanlara 'durumlar' yaşatacağını düşünmüştür. Debord'un önerdiği “durum estetiği”, neo-kapitalist toplumlarda gösteri haline gelen her şeyin içerisinde bir tazelenmenin bulunabileceğe karşılık gelmekteydi. Jean Baudrillard ise "simülasyon" düşüncesiyle gerçekliğin aradan çekildiği imgeler dünyasında yaşanıldığını söylemiş, göstergelere dönüşmüş olan yaşantı içinde sanatında uyumlaşmış olduğunu iddia etmiştir. Bu çalışmada üç düşünürün kilit kavramları ve önermeleri ile sanata getirdiği tanımlar ele alınacak ve bazı açılardan eleştirisi yapılacaktır.

Anahtar Kelimeler: Kültür Endüstrisi, Gösteri Toplumu, Simülasyon, Sanat, Kültür

\section{CULTURE AND ART AT ADORNO, DEBORD AND BAUDRILLARD}

\begin{abstract}
In his thoughts regarding culture industry, Theodor Adorno described art as a "refuge," and suggested that the effect of mass culture on art should be minimized, and that art should remain outside mass culture's influence. In his views on the "society of spectacle," Guy Debord described that everything in present-day culture is turned into a spectacle, and that artistic expression is a form of individual experience that allows people to experience different "states." According to the concept of the "esthetic of state" proposed by Debord, everything that is turned into a spectacle in neo-capitalist societies can lead to a form of rejuvenation. In his views regarding the concept of "simulation," Jean Baudrillard stated that people experienced a world of symbols from which reality fades away or is absent, claiming that art helps harmonize a life and existence filled with symbols. In this study, we will evaluate the key concepts and theses proposed by three philosophers along with the definitions they bring to art, and discuss them from a critical standpoint.
\end{abstract}

Keywords: Culture Industry, Spectacle Society, Simulation, Art, Culture 


\section{Giriş}

Alanlaşmaların (bilim, sanat, felsefe gibi) görüldüğü ve bunların kendi özerkliklerini meydana getirdiği bir proje olarak modernleşme her alanın kendi sınırlarını çizmesine olanak verirken alanların sınırlarını sürekli olarak belirlemek (mesela "sanat nedir?" sorusu gibi) ve sınırlarını korumak (mesela sanatın toplum için mi yoksa sanat için mi olduğu tartışması gibi) zorunda bırakmıştır. Bu durum özgürlük vaadi kadar şeyleşmenin, yabancılaşmanın, homojenleştirmenin, metalaşmanın sürekli kol gezdiği ve kurumsal düzeyi olan iktidardan söylemlerde saklı, görülmesi imkânsız olan iktidar düşüncelerine kadar yönetilen bir kültürü de karşımıza çıkartmaktadır.

Böyle bir kültürde sanat ya kültürün bu düzenlerine uygun şekilde düzenlenmekte ya da tersi şekilde kültüre uyum göstermemektedir. Bugüne kadar gelen ve olmazsa olmaz olarak kabul gören eleştirel sanat, politik sanat ve eylemci sanat gibi kategorilerle sanatsal pratikler kültürden duyulan sıkıntıları, kültürün soykütüklerini yaparak, ideolojilerin illüzyonlarını ifşa ederek ve dışlananların seslerini duyurarak ifade etme yoluna gitmiştir. Bir zamana ait olanları dirilten veya bir yol haritası olarak bunları kullanan, nostaljik şekilde kültürü kurma isteğinde olan, geleceğe dönük bir proje olarak kültür düşünceleri öneren kültürün kendi işleyişlerini kökten değiştirme arzusunda olan ya da bir başka yol olarak kültürün düzenlerinin kaygan noktalarını kullanarak anlık dönüştürmelere neden olan, kültürü performatif hale getiren, kodlarının güçleriyle oynayan sanat tavırları, kültürün hoşnutsuzlukları olarak anlam kazanır. Buna karşıık ise özellikle yirminci yüzyılın ortalarından itibaren eleştirel gücü olmayan, piyasa değerleriyle kolaylıkla uyumlaşan bir sanat fikri de yaygın bir söylem halini almıştır.

Eleştiren ve oturmuş tüm değerleri yıkma arzusunda olan sanatın ardından sanatın sadece tüketim kültürüne hizmet ettiği düşüncesi keskin, genelleyici ancak yaygınlık gösteren bir fikirdir. Böyle bir fikrin (buna 'sanat sıkıntısı' da denilebilir)sanata dair eleştirisi, onun sahici olmayan ve kolaylıkla şeyleşebilen, içeriği gibi biçiminin de dağılabilen bir karakter göstermekte olduğudur. Sanat, yönetilebilen ve etkilerinin nereye varabileceği önceden belirlenebilen bir etkinliktir artık. Elbette bu düşünceler göz doldurur şekilde haklılıklar taşırlarken, piyasa-sanat, sanat kurumu-sanat gibi karşıtıılar etrafında da şekillenmektedir. Bu gibi düşünceler moderniteye veya modern olmaya içkin bir tavrın ürünü olarak da görülebilir. Bu çalışma ise bunu örnekler şekilde kültür ve sanat ikilisi içinden sanatın durumlarını ele almayı amaçlanmaktadır. 
Bu çalışmada kültür-sanat ikilisi üzerinden düşünen üç farklı ancak kimi yönlerden birbirlerini izler gibi duran üç ismin, Theodor Adorno, Guy Debord ve Jean Baudrillard'ın düşünceleri ele alınacaktır. Bu üç ismin gereklilikleri sanatın değişimlerini kültürün değişimleri olmadan düşünmemeleridir. Bu bakış açısı günümüzdeki 'sanat sıkıntısının', eserler karşısında onların sadece piyasaya angaje olduklarını düşünmenin nedenlerinin sahici sanatın ve sanatçının kalmadığı gibisinden açıkçası bir üst dil haline gelmeye müsait ve dolayısıyla da başka bir tahakküm düşüncesine dönüşebilecek bir duruma karşlık başka perspektifler sunmaları ya da düşünmeye davet etmeleriyle değerlidirler. Üçünün de sanata verdikleri roller, her ne kadar Baudrillard'ın karamsar söylemleri diğerlerinden farklılık gösterse de, aynı zamanda sanatın kültür içindeki konumlarını düşünmede değerlidir. Bu çalışmada da bu düşünürlerin bazı anahtar kavramları ve bağlantıları ele alınırken önerilerinin betimlemesi ve kimi yönleriyle eleştirisi yapılacaktır.

\section{Kültürün Üretimi ve Sahnesi}

Frankfurt Okulu, kapitalizmin meydana getirdiği kültürü ve onun etkilerini incelemeyi amaçlarken gittikçe güçlenen ve adı kitle kültürü olan bir düzeneği karşısında bulmuştur (Jay, 1989: 69-75). Adorno ve Horkheimer, "Aydınlanmanın Diyalektiği" adlı eserlerinde tüm bu sürecin başlangıcının aydınlanma düşüncesi olduğunu öne sürerek onun köklü bir eleştirisini yapmışlardır (Adorno ve Horkheimer, 2010). Daha sonraları Adorno'yla anılacak olan 'kültür endüstrisi' düşüncesinin de ilk kez geçtiği bu kitap, kısaca aydınlanmanın akla verdiği özgürleştirici gücün aslında yeni bir tahakküm meydana getirme ile sonuçlandığını ve bu tahakkümün kültürün her yerinde varlık gösterdiğini anlatmaktadır.

Adorno için kültür endüstrisi, kitle iletişim araçlarının (telefon, radyo, telgraf gibi) meydana getirdiği bir ortamın içinde kültürün, bireylerin ve sanatın yaşadığı değişimleri anlatmaktadır. Kitle iletişim araçları iletişimin ve bilginin yayılım göstermesiyle yeni bir evrenin oluşmasında önemli olurlarken, aynı zamanda demokrasi illüzyonunu da var etmişlerdir (Adorno, 2009: 48). Bu yanılsama basitçe, bir şeyleri gizlemeyen, bireylerin böyle bir düşünceye bile kapılmalarının engellenmesi adına her yere nüfus eden etkidedir. Propaganda düzeyinde kalmayan kültür endüstrisi, özneleşme sürecine de müdahildir (Ray, 2014: 246). Ancak kültür endüstrisi bu etkileri meydana getirirken kendisi tamamen gizleyen bir gizemli el gibi işlememekte, şeffaflaşan bir karakter de göstermektedir.

Tekel koşullarında tüm kitle kültürü kendi içinde özdeştir ve bu kültürün iskeleti, yani tekel tarafından imal edilen kavramsal ana hatları belirlemeye başlamıştır. Dönemin başındakiler, tekelin varlığını ört bas etmek konusunda artık kaygı duymamaktadır; 
öyle ki varlığı itiraf edilirken ne kadar arsız olunursa gücü o kadar artar. Sinema ve radyo günümüzde kendilerinin sanatmış gibi göstermek zorunda değildir. Herhangi bir işten farklı olmadıkları hakikatini, bilerek ürettikleri zırvaları meşrulaştıran bir ideoloji olarak kullanırlar. Onlar kendilerini endüstri diye adlandırırlar ve görevin başındaki genel müdürlerin gelirine ilişkin rakamlar kamuya ilan edildiğinde, tüketime hazır ürünlerin toplumsal gerekliliği konusunda kuşkular dağılır (Adorno, 2009: 48).

Yüksek kültür ile düşük kültürün birleştirildiği ve zayıflatıldığı kültür endüstrisinde her şey birbirine benzemektedir (Adorno, 2009: 110, 47). Benzerliğin üstünü ise sürekli olarak kitlelerin kendisine sunulanları kabul etmesi için ilgilerini diri tutan her şeyin yeni ve farklı olduğu kanaati örtmektedir (Adorno, 2009: 109). Kültür endüstrisi bireylere sunduğu sürekli yenilik illüzyonu kadar kültürel birikimleri kökten etkilemesiyle de önemli bir olgudur.

Modern hayatın yeni kültürü olan kültür endüstrisi her türlü eylem ve bilincin kökenidir. Bunu da aydınlanmayla olan karın bağından, akılcılaştırmanın sonucu olan pragmatik ve araçsal akıl ile gerçekleştirir. Adorno için kültür, aydınlanma döneminin ertesinde yükselen burjuva ile nötrleşmiş, "mevcut olana karşı sivriliği törpülenmiştir" (Adorno, 2009: 132). Çünkü kültür endüstrisi de her şeyi planlayan ve hesaplayan, olağan dışı unsurların kendince var olmalarına izin vermeyen bir işleyişe sahiptir. 1960 yılında "Kültür ve Yönetim"de Adorno, özneleşmenin "nesnel disiplin"le, uzmanların düzenlediği bir yönetim içinde gerçekleştiğini ve bireyin kültürü tüketirken onun tarafından da manipüle edildiğini yazar (Adorno, 2009: 147). Bütünleşmiş ve kontrol edilen, uzmanlarınelinde varlık bulan kültür, "maddi yaşamın yeniden üretilmesine, kelimenin tam anlamıyla insanın varlığını sürdürmesine, onun yalın varoluşunun korunmasına yarayan her şeyin" karşısında olmaktadır (Adorno, 2009: 122, 123). Kültürün yönetiminde alanlaşmalar ile farklılıklar tamamen sona erdirilirken bürokrasi her şeyi kapsayan düzenini de yayar. Bu yüzden sürekli olarak yönetim, uzmanlar üretmeyi amaçlar. Eğitim uzmanlık amacıyla kurgulanır. Kişisel beceriler ve yetenek uzmanlaşma için yeniden nitelikler kazanır (Adorno, 2009: 127).

Kültür endüstrisinin sarmaladığı her şey kendi içinde erimeye mahkûmdur. Adorno, kötümser bir tonla bir dizi kategorinin kültür endüstrisinde nasıl elendiğini, nasıl içinin soğurulduğunu şu şekilde ifade eder:

Kültürel kavramının olumsuzlanması, kendini hazırlıyor. Bunun başlıca bileşenleri: özerklik, kendiliğindenlik, eleştiri gibi kavramların hükümsüzleşmesi. Özerklik: 
çünkü özne, bilinçli karar vermek yerine, önceden belirlenmiş olana boyun eğmek zorundadır ve bunu ister; çünkü geleneksel kültür kavramı uyarınca kendisi yasa koyması gereken tin, salt var olanın ezici talepleri karşısındaki güçsüzlüğünü her an deneyimler. Kendiliğindenlik ortadan kaybolur: çünkü bütünün planlanması bireysel heyecandan önceldir, onu önceden belirler, bir görünüşe indirger ve özgür bir bütünü doğurması beklenen güçler oyununa artık hiç tahammülü yoktur. Son olarak eleştiri de yok olur, çünkü kültürel olanın modelini giderek daha çok belirleyen bu süreç içinde, eleştirel zihin, makinedeki kum kadar rahatsızlık vericidir (Adorno, 2009: 140).

Okuyucusunun bu pasaja yöneltebileceği soru, her şeyin kolaylıkla plana dâhil edildiği yerde bunun karşıtının yaşama gücünün olup olmayacağıdır. Adorno, birkaç sayfa sonra bu soruya kendiliğinden olanın, planlanmamış olanın varlığı her ne kadar olağan olsa bile onun da kültür endüstrisi içinde konumlandırıldığı şeklinde cevap verir. Öyle ki özgürlük bile kurgusal bir hal alabilmektedir (Adorno, 2009: 144). Kendisine ait bir alan ve bir dil meydana getirmesi adına planlanmamış olanın kültüre içkin yönetim tarzlarından kaçmanın yolu neredeyse mümkün değildir.

Adorno gibi Guy Debord' da modernizmin teknikleştiğini düşünenlerdendir (Debord, 1996: 28). 1960'lı yıllarda Debord, kültürün gösteri halini aldığını, onun temsillerle varlık bulduğunu ve imgelerin kökensiz hale gelerek birer gerçeklik ürettiğini düşünür. Kültür, kapitalist sistemde bölümlenen, "yapma" ile "kavrama" nın birbirinden ayrımlaştığı, emeğin küçük parçalara dağılarak yeniden bir araya getirildiği ve yabancılaşmanın yanılsamalı şekilde kapatıldığı bir alandır (Canjuers ve Debord, 2011: 324, 325). Debord, gösterinin "hem bizzat toplum olarak, hem toplumun bir parçası olarak ve hem de bir birleştirme" aracı olduğunu yazarken kültürün işleyişini, tıpkı Adorno'daki gibi, varoluş ile ilgili görür (Debord, 1996: 14).

Gösteri, deneyimlerin nesneleşerek konserve edilmiş halidir. Gösteri, duyumsal dünyanın yerine geçmesi, "en mükemmel duyumsal olarak kabul" edilmesidir (Debord, 1996: 14, 25). Kapitalist pazarın palazlandığı on dokuzuncu yüzyılda metanın büyüleyici hale gelmesinin diğer bir adı olarak gösteri, metanın esas olan yönüdür (Debord, 1996: 30). İhtiyaçlar, çeşitlendirilmiş göz alıcı metalarla farklılaştırılırken, metayı saran ve belki de onu aşan gösteri, tüketici hale gelen bireyin içine düşeceği yanılsamalarla devamlılık göstermektedir (Debord, 1996: 29).

Gündelik hayatın üretiminde kapitalist kültürün metalarla sarmaladığı dünya, sadece tüketime dönük bir eylem pratiğini sunmamakta gündelik 
olanı da üretmektedir. Debord'un 'gösteri' kelimesi karşılıklarından birisi de budur. Gösteri, modern teknolojinin ürünü olan görüntüler ağı değil, onların içerdiği görme rejimleri ile beraber "metanın duyumlar ve öznelliğe bütünleştirici bir şekilde nüfuz ettiği dönemde şeyleştirilmesi(dir)", yani "kapitalin duyumsal olarak bölünemez bir hale getirilmiş ve 'haz' olarak doğallaştırımış gücüdür" (Roberts, 2013: 107). Gösteri toplumu da kitle kültürünün bir başka görünümü olarak "maddileşmiş ideoloji"ye karşlık gelmektedir. Öyle ki bu durum, Adorno'nun kültür endüstrisinde ifade ettiği gibi, bireyin bilinçdışı yapısını etkiler güçtedir (Yibing, 2012: 90). Debord'un kültür düşüncesi, Adorno'nun kitle kültürünün dışarısına çıkılamayacağı düşüncesine bu açıdan benzemektedir. Çünkü gösteri, toplumdaki her şeyi kapar. Bu nedenle kültürün kendiliğinden üretimine değil, kendiliğinden olan duyumsamanın bile varlığına izin verilmez.

Debord'un kapsayıcı kültürü, Jean Baudrillard'ın düşüncesinde kültürün geldiği olağan bir durum şeklinde anlam kazanır. Tarihsel bir süreç içinde kültür, geldiği evrede farklı kültürel yaşantılar ve öneriler olmadan varlık bulmaktadır (Gottdiener, 2005: 66). Baudrillard, gelinen noktaya verdiği isim olan 'simülakrlar düzeni'ni, tarihin bir seyri gibi dönemlere bölerek okuyucuya anlatır. Bu tarihsel dönemselleştirme "biçim kopyalama"nın olduğu Rönesans dönemi, "üretim" in hakim olduğu sanayileşme dönemi ve "kodun belirleyici" olduğu simülasyon düzeni şeklindedir (Baudrillard, 2002: 78).

Baudrillard, ilk dönem düşüncesinde tüketim toplumunu meta-gösterge teorisiyle ele alır (Featherstone, 1996: 120). Bu teorik bakış, kültürün arka planında ekonominin değil, kültürel boyutun kendisine yönelir (Gottidiener, 2005: 66). Tüketim toplumu düşüncesi sanayi kapitalizmden bu yana gelen tüketim düşüncelerine ek olarak bireylerin arzularına seslenen bir meta düzeni olduğunu, bireylerin göstergesel düzeyde de bir tüketim içinde yaşadığını, gerçekliğin ise estetize edildiğini anlatmaktadır (Featherstone, 1996: 119). İşte bu estetize ediş (bu fikrin Frankfurt Okulu'na yabancı olmadığı unutulmamalıdır) kültürün genel karakterini, gerçekliğin etkilerinin azaltıldı̆̆ını göstermesi adına önemli bir nokta sunmaktadır.

Adorno'nun şahit olduğu kapitalist düzen “bu kez her şeyi (yaşamın tüm alanlarını) denetlemek isteyen, sibernetik özellikler taşıyan neo-kapitalist bir düzene geçmiştir" (Baudrillard, 2002: 94). Kapitalizm ile beraber birey, nesnelerle kuşatılırken sadece nesneleri kullanmayıp onlarla kimliğini kazanmakta ve onlarla varlık bulmaktadır. Buna karşılık Baudrillard'ın önerilerinden biri öznenin konumunu nesnenin ona hâkim olması şeklinde yeniden düşünmeye davet etmek ve öznellik hallerinin sürekli olarak 
kaygan bir şekilde varlık bulması gerektiğini söylemek olur (Sarup, 1997: 230). Ancak Baudrillard'ın önerisi, Adorno ve Debord'unkiler kadar kesin ve güçlü değildir. O daha çok neo-kapitalist toplumların geldiği kültürel durumun vahametini betimleyen ve her önerinin buna katkı yapmaktan başka bir gücü olmadığına inanmaktadır.

\section{Sığınak, Durum ve Hiçlik Olarak Sanat}

Eğer kitle kültürü bireylerin tüm kanaatlerini, estetik seçimlerini, etik ve politik kısacası tüm ifade imkânlarını önceden belirleme gücündeyse, kendi karşıtı olanları kolaylıkla soğurup dondurabiliyor, onları kendi sahnesinde sergileyebiliyor, kendine mal edebiliyorsa ve kitleler kültüre karşı eleştirel bir mesafe oluşturamıyorsa böyle bir kültürde sanat ne yapabilir? Adorno, avangard sanata güven beslemekteydi. Debord da sanatsal ifadeyle siyasal eylemciliği bir arada önermekteydi. Baudrillard ise anlatısını yaptığı sistem içinde sanata bu iki düşünür gibi esaslı roller biçmemekte, her şeyin simülasyona dönüşerek etkisiz olduğunu ilan etmekteydi.

"Aydınlanmanın Diyalektiği"nde Adorno ve Horkheimer, sanat yapıtının hala büyüsel özellikler taşıdığını savunurlar:

[Sanat yapıtı] Dışkutsal [profan] var oluş bağlamından uzak, kendine ait kapalı bir alan oluşturur. Bu alanda özel yasalar geçerlidir. Nasıl tören sırasında büyücünün ilk işi kutsal güçlerin harekete geçireceği mekânı bir sınır çizerek çerçevesindeki her şeye kapatmaksa, sanat yapıtı da kendi çemberiyle gerçekliğe kapanır. Sanatı büyüsel sempatiden ayıran özellik etki yaratmaktan vazgeçmesidir; ama tam da böyle yapmakla büyünün mirasına daha da sıkı sarılmış olur. Bu vazgeçiş saf imgeyi cisimsel varoluşa karşıt bir konuma yerleştirir ve imge kendi içinde var oluşun öğelerini etkisizleştirir. Estetik görünümde de, sanat yapıtının özünde de yatan, ilkellerin büyülerindeki yeni, dehşet verici bir olayın çıkardığı şeydir: bütünün özelde görünmesi (Adorno ve Horkheimer, 2010: 38).

Bu pasaj, hayat ile eser arasındaki sınırları belirginleştirmesiyle Adorno'nun sanat düşüncesinin özetlerindendir. Adorno için sanat, hakikate dair söyleyecekleriyle özerktir ve bu özerklik, büyüsellik gibi yaşama dairdir. Eserin hakikat ile ilişkisi "başka türlü olabilir" in önerisi olmasıdır (Eagleton, 2003: 426) ve böyle bir sanat, kitle kültürünün ürettiği sanat ile karşıtlık oluşturmaktadır (Adorno, 2009: 58). Bu yüzden kitle kültürünün sanatı ile toplumu eleştiren, içinde başka dünyalar barındıran, şeyleşmeye ve yabancılaşmaya karşı direnen sanat arasında bir ayrıma gitmek gerekmektedir (Slater, 1998: 232, 233). Ancak kültür endüstrisinde toplumsal mantıktan ayrı olması gereken yapıtın mantığı "feda edilmiştir" (Adorno ve Horkheimer, 2010: 164). Yapıtın özerkliği toplumun eleştirisi 
veya ona bir başka yol gösterme imkânına sahip olma potansiyeline sahip iken kültür endüstrisinde bu durum kitlenin isteklerine uygunlaşan yapıta karşılık gelmektedir. Yeteneğin izleyici önüne önceden hesaplanmış ve belirlenmiş şekilde getirilmesi, yapıtın düzeni ile toplumsal düzenin mantığının bir araya getirildiğinin göstergesidir (Adorno ve Horkheimer, 2010: 164). Filmlerin başı ve sonu belli olduğu gibi şarkılarında ritimleri ve melodileri önceden belirlenmiş bir estetik tepkiyi içinde barındırmaktadırlar. Eser de sunduğu fanteziyle, içine sığınılacak ve gerçeklikten kaçınılacak bir yuva halini almaktadır. İzleyicinin eser karşısındaki üretici konumu da onu sadece izleme ve keyif alma, hayal gücünden yoksun şekilde ona katılma ile sınırlıdır (Adorno, 2009: 55).

Böyle bir noktada sanatın varlığı, Adorno'nun ünlü metaforuyla onun 'sığınak' olmasıyla anlam kazanmaktadır (Altuğ, 2012: 198). Sı ̆ıınak olarak sanat, içinde bir zamanlara ait olan kültürde kristalize olmuş bir estetiği ve biçimleri taşıması anlamında düşünülmemelidir. Sanat, kültürün geçmişine dönmektense, hali hazırda kültürü düzenleyebilir ve bütünlüklü bir yaşantı önerebilir (Dellaloğlu, 2003: 50). Eserin içerdiği bu hakikat, kendisindeki negatiflikle topluma karşı eleştirel bir duruş sergilemesine yardımcı olur (Zima, 2004: 155). Böyle bir sanat ise Adorno'nun eleştirdiği caz müziği, Hollywood melodramları değil avangard sanattır.

Avangard sanat, özerkliktalebiyle toplumun düzeneğini eleştirecekgücü kendisinde bulmakta ve bu güç ile "ütopyacı bir hakikat içeriği elde" edebilmektedir (Altuğ, 2012: 196). Avangard sanat eseri, kendi söz dizimini meydana getirerek kültür endüstrisinin yönetilen ve hesaplanabilir işleyişinin dışında yer alabilir (Adorno, 2009: 57). Böyle bir yapıt izleyicisi karşısında yabancısı olacağı etkiler meydana getirme gücüne eriştiği zaman hem kitle kültürüyle mesafesini korumuş olur hem de bireyin yabancılaşmasını sağlar. Böylelikle kültürün yabancılaştıııcı etkisinden başka bir yabancılaştıııcı etki, negatif bir güç varlık bulur. Bu güç eserin tümüne nüfus edilememesiyle ilgilidir. Kitle kültürünün sanat gramerinin tersine sanat eseri kavramsallaştırılamaz olanın ürettiği bu direnç, eserin donuklaşmasınıda engeller (Zima, 2004: 153). Adorno'nun sanat yapııının direnci, gerçekliğin düzenlerini titreştirmesi ve dolayısıyla kültürün illüzyonik yönünü göstermesiyle de değerini bulmuş olur.

Adorno'nun düşüncesinde önemli yer tutan mimesis kategorisi, öznenin eserde bir başkasıyla karşılaşmasıdır (Altuğ, 2012: 198). Dile gelmez olanın eserde varlık bulmasıyla izleyici eserin içinde erir (Altuğ, 2012: 200). Çünkü kültür endüstrisinin karşısındaki sanat, "salt Varlık (Sein) değil; daha çok, özne ve nesne arasında bir güç alanıdır" (Adorno, akt: Jay, 1989: 257). Böyle bir sanat verili olandan hareket etmeyerek didaktik bir yanılsama üretmediği gibi bakışın seyir odağında konumlandığı bir alan üretmemiş olur (Dellaloğlu, 2003: 88). Eserin 
karşısında izleyicinin edimi dekültürün düzenlerini yeniden yorumlamak adına kendisini eserin içine dâhil etmesiyle şeklini kazanır.

Estetik deneyimin katılımcı boyutu izleyicinin dinledikleri, gördükleri ya da okudukları karşısında belirlenmiş olan hazzı alması değildir. Mesela "Schönberg'in müziği, dinleyiciden, müziğini içsel devrimini müziği dinlerken yeniden kendisinin de kompoze etmesini gerektirdiği gibi, ondan yalnızca müzik dinleme hazzını duymakla yetinmeyip, praxis'te bulunmasını da" istemektedir (Adorno, akt: Jay, 1989: 255). Kafka'nın metinleri de Schönberg'in müziği gibi okuyucusunu kendisineyaklaştıran bir gücesahiptir. Okuyucu, Kafka'nıneserlerinde kayboluyorsa bunu gerçekliğin betimlenmesindeki realizmle değil onu yorumlamak zorunda olmasıyla yaşamaktadır (Dellaloğlu, 2003: 89). Kafka'nın eserleri, izleyiciye sunduğu yabanclıkla yaşadığı hayata görmediği bir noktadan girmesini sağlar ve sanat kendi içsel düzeninde hayatı yakalayarak onu düzenleme yoluna gitmiş olur (Eagleton, 2003: 426).

Kültür endüstrisi bireyleri en sıradan itkisel düzeydeki tepkilerinden uzaklaştırma görevinde olmuştur. Dünya savaşları içerisinde avangard hareketlerin yıkılan bir dünyanın yeniden tesisi için gerekli olan olarak gördükleri bireyi tazelemesi bu açıdan değerlidir. Ancak dünya savaşları ertesinde kendisini tamir etmeye çalışan batı kültüründe avangard sanatçı gücünü yitirmiş gibidir. 1960'lı yılların Debord'u böyle bir iklimin etkileriyle sanatın bağımsızlaşmasını, modern sanattaki bireyselleşmeyi sanatın çözülmeye başlaması anlamında görmekteydi (Debord, 1996: 100). Debord'da Adorno'daki gibi praksisin asıl olduğu bir çözüm önerir:

Illetişim dilinin kaybedilmesi; işte her türlü sanattaki modern ayrışma hareketinin, yani biçimsel yok oluşun olumlu anlamda ifade ettiği şey budur. Bu hareketin, olumsuz anlamda ifade ettiği şey ise ortak bir dilin yeniden keşfedilme gerekliliğidir; ama bu dil tarihsel toplumun sanatında her zaman için çok geç kalan, yaşanmış olanı gerçek diyaloğa yer vermeden diğerlerine anlatan ve yaşamın yetersizliğini kabul eden tek yanlı çözümde değil- doğrudan eylem ile bu eylemin dilini kendi içinde toplayan praksiste keşfedilmelidir. Burada, şiirsel-sanatsal eserlerle temsil edilmiş olan diyalog topluluğuna ve zamanla oynanan oyuna gerçek anlamda sahip olmak önemlidir (Debord, 1996: 101).

Debord, sanatın ortak dil üretebileceği önerisini sunarken düşülen hatanın, yaşamın kuru ve donuk bir anlatıı olduğunu buna karşı ise eylemin asıl olması gerektiğini düşünmekteydi. Avangard akımlar izleyicisinin yabancı kaldığı, şoke ettiği parçalar üreterek ortak dil adına kendince bir öneri meydana getirmişlerdi. Ancak hayatın tek biçimli yaşanamayacağı, anlam düzenlerinin üst dillerle belirlenmiş olduğu ve bunların sürekli akışlar ile bozulabileceği şeklinde özetlenebilecek bu öneriler emilerek kültür içinde uysal hale getirilmiştir (Debord, 2011: 339). Modern sanatın başına 
gelen eleştirel tutumun kültür içinde eritilmesi karşısında Debord, sanatın ürettiği formları sürekli eleştirel bir yaklaşımla düşünür. Sanatın formlarının kolaylıkla gösteriye dâhil edilebileceği, içeriğinden soyutlanarak basit birer gösteri haline gelebileceğini düşünen Debord, bu yüzden modern sanatın düştüğü durumdan ders çıkartılması gerektiğini yazar:

\begin{abstract}
Dadahareketiyle doruknoktasınaulaşanmodern sanatın devrimciişlevi, dildeneyleme sanattaki bütün uzlaşımları ortadan kaldırmak oldu. Gelgelelim, sanattaki felsefede yok edilenler henüz somut biçimde gazetelerden ve kiliselerden temizlenemediği için, ve silahların eleştirisi o dönemde eleştiri silahlarında gerekleşen ilerlemeleri takip edemediği için, dadaizmin kendisi, kabul görüp onaylanan bir kültüre stil olmanın ötesine geçemedi. Hatta Dada formu, 1920'dern önce icat edilmiş stili ele geçirip kariyer yapan her ayrıntıyı muazzam ölçüde abartarak sömüren neodadaistlerin elinde geçici bir reklam aracına dönüştü ve mevcut dünyanın kabul edilip benzemesine hizmet etti (Debord, 2011: 342).
\end{abstract}

Debord'un konumu bilinen anlamda sanatçı olmaya dair değildir (Wark, 2014: 82). Debord, avangardların anti-sanat düşüncesini devam ettirenlerdendi. İçinde bulunduğu Sitüasyonist hareket ve ondan önce gelen Letrist Enternasyonel için 'sanat yapmak' deha sanatçı kültüne, biricik gizemli eser düşüncesine karşı olmaktır (Marcus, 1999: 186). Güzellik, Letristler için "sadece ve sadece duyumların, yani geçici olanın, yaşanmış olanın yaratacağı bir güzellik olacaktır" (Marcus, 1999: 191, 192). Debord'da bu düşünceleri devam ettirmeyi asıl görmekteydi.

Debord'un 'gösteri'kelimesi kadar, 'durum' kelimesinin de O ve diğerlerinin anlayışları hakkında fikir verici olduğu söylenebilir. Durum, olay olma haliyle, gösterinin gelinen noktayı betimleyen keskin hatlarına karşıt sürekli elden kaçan bir anlama sahiptir. Bu yüzden durumun 'olay' hali 'şimdi'yi deneyimlemek olarak biçimsiz ve devinim şeklindeki algılamaya müsait bir anlam sunuyor olsa bile eksik kalmaktadır (Perniola, 2015: 94). Olayın izler halindeki varlığının ertesindeki kalıntılar ne kadar güçlü etkiler sunuyor, Debord'un avangard akımların stratejilerinin kültürdeki donuklaştırmasına ters şekilde düşünülmesine olanak veriyor olsa bile bu anlam kesin bir karşılık sunmaz. Durumun olay hali daha çok "iç ile dış, öznellik ile dünya arasındaki karşıtlığa tutsak kalmak yerine, kişiliğimin ötesine giden bir sürece yerleşmemi sağlayan yapıcı bir çözüm"e karşılık gelmektedir (Perniola, 2015: 96).

Sitüasyonistler, anti sanat düşüncesini sürdürürken gösteri toplumunda bireyin yenilenmesinin estetik bir proje ile düşünmüşlerdir. Olay işte 
bu estetiğin karşılı̆̆ıdır. Olay, 'şimdi' içerisinde geleceğe ait bir proje olmadan bireysel bir deneyim halinde yenilenme, dünya karşısında bireyin şaşkınlık yaşamasıdır (Perniola, 2015: 93). Bu açıdan durum, praksise katılan izleyicinin seyrinin tamamen bozularak içe daldığı gösterinin yeniden duyumları hazır olan imgelerinin kültürün karmaşık ideolojik düzenlemelerinin elinden alınmasıdır. Yani gösteri toplumunun düzeninin bozulması kültürel alışkanlıkların yeniden düzenlenmesi adına bireyin durumlar içinde başkalaşması olarak değerlendirilebilir. Debord ve diğerlerinin önerileri kültürü kurmak adına onu bozguna uğratmak için radikal bir eylemci planı olarak özetlenebilir. Bu eylemci tavrı anlamak için öne sürülen birkaç yöntemden söz etmek gerekmektedir:

Sanat yapmak, onun bir zamanlar adına konuştuğu ortak, gömülü istekleri tekrar ortaya çıkarmak demekti, ama çalıntılama tekniğini uygulamaya sokmak gazetelerdeki karikatürlere veya aynı nedenle eski üstatların yapıtlarına konuşma balonları yazmak; bu harekete eşzamanlı olarak sanatın "değersizleştirilmesi" ve yeni bir toplumsal hitabet biçimi olarak "yeniden yatırımı" konusunda ısrar etmek; "bünyesinde kendine özgü bir eleştiri biçimini barındıran bir iletişim" olduğu, biçimi tümüyle demistifikasyon olduğu için mistifiye edemeyen bir tekniğe sahip olduğu fikri üzerine ısrar etmek - ve gelişigüzel sürüklenmek (dérive)- kendini şehrin vaatlerine bırakmak ve vaatlerin eksik olduğunu görmek-, şehir içinde gelişigüzel dolaşmak, yön levhalarının kendi kendilerine yönlenmelerine izin vermek, adımlarını "değiştirerek" atmak bu levhaları daha önce hiç var olmamış bir güzergâha yönlendirmek; tüm bunlar, sonu olmayan bir değişimdi. Bu, kaldırım taşlarından ve resimlerden, sözcüklerden ve havadan sudan şeylerden kurulu gerçek anlamda modern bir hayat yaşamaya başlamak demekti: Herkesin anlayabileceği, herkesin yararlanabileceği bir hayat biçimi (Marcus, 1999: 187).

Deneysel ve devrimci bir hareket olan, yaşamı pratik ve kuramsal açıdan yeniden inşa etme amacında olan Sitüasyonist hareket, gösteri toplumunun sarmalayıcılığı içinde bireyi kendi tarihiyle buluşturmak amacındaydı (Debord, 2011: 335, 336). Bu yüzden Debord "durumların yıktığı" düzenler ile (Marcus, 1999: 180) akademik düzeyde sıkışacak ve geleceğe kalacak bir sanatı önermiyordu. Debord için teorik açıdan kültüre yaklaşmak ve aktivist bir tavır göstermek gösteri toplumunun ürettiği hazır deneyimlerle sarılı yaşantıyı kırma gücüyle asıl olmaktaydı (Debord, 2011: 341).

Adorno'nun Kafka'da ya da Schönberg'de bulduğu yenilenme ve kitle kültürünün şeyleşmiş halinden kaçma, Debord'da izleyicinin/bireyin şehir mekânında karşılaştığı mesajları çalıntılayarak değersizleştirmeyle, bedenin kendiliğinden yolunu kaybetmiş gibi davranmasıyla karşılanmaktadır. 
Hepsi de toplumun yenilenmesi ve ortak bir dil içindir. Bu nedenle Sitüasyonist Enternasyonel'in kendisini kökten eleştirel bir perspektif belirleyip "unutulmuş arzuları gün ışığına çıkarmaya ve tamamen yeni arzular yaratmaya" (Chtcheglov, akt: Marcus, 1999: 192) neden kendini adamış olduğu daha net anlaşılabilir.

Baudrillard, otuzunda sitüasyonist iken altmışlardaki halini betimlemek için gerçek ile kurgu arasındaki sınırın belirsizleştirdiğini söyler (Lotringer, 2010: 18). Adorno ve Debord'un karşı çıkmasına karşılık Baudrillard, şeyleşmeyle bir "sözleşme" yapmış gibi (Best ve Kellner, 1999: 310) her şeyin sonunu müjdeler. Sanat da neo-kapitalist toplumlarda tüm güçleri elinden alınmış ve sadece estetik gösteri haline gelmiş bir etkinlik olarak, sonu gelmiş olanlar arasında en iyi örneklerinden birisi olur.

Sanat, simülakr düzeninde simülasyona dönüşmüştür: "Bizlerbir simülasyon dünyasında yaşıyoruz, göstergenin en büyük işlevinin gerçekliği kayboluşa itmek ve bu yolla onun kayboluşunun üzerini örtmek olduğu bir dünyada" (Baudrillard, 2010: 36). Sanatın konumu gerçekliğin olmadığı durumda onun varlığını hissettirmeye çalışmak ya da tekrar onu göze getirmeye çalışmak değildir. Sanat, kurtuluş için, gerçekliğe müdahale etmek, dönüştürmek ve gerçeklik algılamaları gösterebilmek için denemelerde bulunsa bile bu nafiledir. Çünkü imgeler gerçeklikten koparak ve kendisi olarak varlık bulmaktadırlar (Baudrillard, 2010: 37).

Geleceğe dönük bir projeksiyon, sanatın bir ütopya hali sunması yerini geçmişe doğru bir bakışa bırakmıştır. Sanat, geçmişi yerinden ederek, onu temellük etmekte, geçmişine göndermelerde bulunarak gerçekleşmektedir (Baudrillard, 2010: 27). Bu durum, geçmişin birikimleri üzerinde yükselen yeni bir dilin üretimi, geçmişle hesaplaşma ya da onun devamı olarak üslup arayışı anlamına gelmemektedir. Geçmiş şimdi içinden tüketilen, ironisi yapılan bir hal almıştır (Baudrillard, 2010: 28). Modernist sanatın bazı açılardan nostaljik tutumu ve geçmişin geleceğe doğru gösterebileceği yol haritası postmodern sanatta sanat piyasasının sürekli yenilik arzusunun deposu olarak geçmişe bakması yolunu kaybetmiş sanatın kendisini tüketmesi demektir.

Baudrillard'ın sanat üzerine görüşlerinden bir diğeri de gerçeklik ve yanılsama sorunları üzerinden sanatçıların imgeyi daha da fazla etkili hale getirmekten başka bir şey yapmadığıdır. Adorno' nun kültür endüstrisindeki sanatın önceden planlanmış olduğu düşüncesine benzer şekilde Baudrillard da sinema sanatını örnek vererek "bir filmde en ufak bir boşluğa, aralığa, eksiltiye, sessizliğe yer" olmadığını "hiperteknik, hiperetkili, hipergörünür" imgenin yanılsamanın yerini aldığını izleyicinin karşısında 
mükemmelleştirilmiş imgeyi gördüğünü yazar (Baudrillard, 2010: 29). Sadece sinema değil çağdaş sanat da Baudrillard için değer olarak 'bayağılık' ile ilgilidir. Sanat, estetik konusunda yeni ve farklı bir duyum, bir fikir ve değişim önerisinde bulunma gücünü elinde tutmamaktadır:

Bu sayısız enstalasyon ve performans, dünyanın mevcut durumuyla ve sanat tarihinin gelmiş geçmiş tüm formlarıyla uzlaşmaktan başka bir şey yapmıyor. Özgünlüğü, bayağılığı ve hükümsüzlüğü değer mertebesine, hatta sapkın estetik haz mertebesine çıkarıyor. Kuşkusuz bütün bu vasatlık, sanatın ikinci bir düzeyine, ironik düzeye çıkarak kendini yüceltme iddiasında. Ama ikinci düzeyde de, en az birincisinde olduğu kadar boş ve anlamsız. Estetik düzeyde de, en az birincisinde olduğu kadar boş ve anlamsız. Estetik düzeye geçmek hiçbir şeyi kurtarmıyor, bilakis, vasatlık katmerleniyor. Sanat hükümsüz olma iddiasında... (Baudrillard, 2010: 51).

Estetik hükümsüzlük, sanatın dünya dönüştürücü iddiası olsa bile onun kolaylıkla soğrulabilir olmasıdır. Modern kültürde ütopyaların ertesinde sanat, gündelik hayata karışarak onun estetikleştirilmesine katılmaktan başka bir şey yapmamaktadır (Baudrillard, 2004: 18). Yani sanatın estetiğin hükümsüzlüğü kaçınılmaz olarak sanatın şeyleşmesidir.

Baudrillard, önerilerin olmadığı, alternatifsiz bir kültürde yaşanıldığını düşünmektedir. En azından kendisi eserlerinde süreklilik izleyen güçlü öneriler getirmemiştir. Sanatın modern kültürde siyaset ile olan ilişkisi ve politik dönüştürücü gücü, estetik deneyimin özel bir alan ile sınırlı kalarak biçimsel bütünlüklerden haz almak değil, yanlış hayatın nasıl doğru hale gelebileceğini önermesiyle ilgiliyken Baudrillard'ın kültür düşüncesinde sanat sadece içe patlamalarla, piyasaya angaje olmaktan öte, onun belirleme gücüyle varlık bulan bir gösteriden ibarettir. Sanat, kültüre radikal bir şekilde yaklaşarak çelişkilerini ve her anlamda bir boşluğun, ayrı bir alanın olmadığını her şeyin farklılıklarının kalmadığı bir düzende yaşanıldığını göstermenin yollarından biri olarakmodernite eleştirisiniyapan Adorno gibi düşünürlerle ortaklıklar sergilemekteydi. Ancak Baudrillard, teorik düzeyde kültüre eleştirel yaklaşan tavırların zamanın gerisinde kaldığını düşünerek onları eleştirmekteydi (Bilgin, 2010: 283). Kültürün iktidar düzenlerini, kaçınılmaz yabancılaştıııcı etkilerini, şeyleştirici gücünü hakikati göstermek adına düzen kazanan sanat düşünceside Baudrillard'ın ileri kapitalist toplumlarında gerilerde kalmış bir tavra karşılık gelmekteydi.

Kitle iletişimin meydana getirdiği etkileri inceleyen Baudrillard, kamusal mekanın ortadan kalktığı gibi kişiye özel iç mekanın da ortada kalktığını düşünür (Sarup, 1997: 234). Bu nedenle de sığınak düşüncesiyle bir dışarısı, içerideki özerk bir alan ya da içerideki dışarıdalık olarak sanat fikrine sahip Adorno'nun karşısında farklı bir konum almaktadır. Baudrillard, 
Adorno'nun sesini hissettirir şekilde, kitle iletişim aygıtlarının gerçek ile taklit arasındaki sınırları silerek, eylem ve kararları engelleme amacında olduğunu düşünmekteydi (Sarup, 1997: 234). Ancak bu engelleme dil tutukluğu içinde kalan bir toplumla, onun sığınacağı bir dış alan düşüncesini barındırmamaktaydı.

Baudrillard için müzeler, modern kültür ile birlikte bozulan aristokrasiye hizmet eden sanatın ve devam eden süreçte kitle kültürüyle ortadan kalkan yüksek sanatın ardından parçaları birleştiren ve kriterler meydana getiren düzenleriyle izleyicisine işaret dizgesinde hareket etmesini istemektedir. Eserler artık anlamlarıyla değerli değildirler (Sarup, 1997: 236). Her şey gibi onlar da birer gösterge olarak akıp gitmekte ve sessizleşmektedirler. Debord'un durum stratejileri Baudrillard için şeyleşmeye katkı sağlamaktan başka bir şey değildir. Her şey ambiyans içindir (Baudrillard, 2004: 23). Sanat göstergeleriyle sadece ambiyans estetiğini yaşatmakta ve geçişken kültürün hazzın düzeni içinde varlık göstermektedir.

\section{Sonuç}

Adorno, kültür içinde eriyemeyecek olan sanatı kendi alanına sahip şekilde tanımlamaktaydı. Konumunun kimi zaman yüksek sanatı kurtarmak olduğunun düşünülmesi ise bu nedenledir. Debord'un böyle bir amacı olmamıştır. $O$, dünyayı değiştirecek siyasi eylemciliği sanatsal ifadeyle kurumsal açıdan sanata düşmemek için değerli görerek, kısmen bu alan ayrımını korumayı devam ettirmekteydi. Sanat, Debord'da Adorno'nun ideolojinin büyüleyici etkilerini bozma tekniklerinden farklı olarak gösteriye saldırarak anlamlarını kaydırma önerisiyle saklı bir hakikati değil, durumların deneyimlemesini sağlama görevindeydi. Baudrillard ise sanatın kendine özgü bir alana sahip olabileceğini düşünmemekteydi. Sanatın gerçekliğe dair söyleyecekleri ve onu değiştirecek bir gücü olduğunu da düşünmüyordu. Anlatısını kurduğu simülasyon kültüründe de sanatın özerkliği olamazdı. Gerçekliğin kendisinin görünmez olduğu bir zamanda sanatın gerçekliği kurtarmak ve onu yeniden inşa etmek gibi bir gücü veya ütopyası da olamazdı. Bu nedenle Debord'un önerdiği yeni deneyimler Baudrillard'ın ileri kapitalist toplumlardaki deneyimlerin steril halinden kaçamaz.

Debord, 'durum' ile belki de avangardın ertesinde son etkili stratejilerinden birisini önermiş oluyordu. Bugün ise 'durum' gibi sitüasyonist stratejilerin yaygınlık göstermesini olağanlaşma olarak yorumlamak mümkündür. Çağdaş sanat içerisinde sitüasyonistlerin sanatın gözden düşürülmesi adına kullandıkları teknikler "manipüle" edilerek sanatsal bir üretim içinde kullanılmaktadır (Borriaud, 2004: 61). Baudrillard'ı haklılaştııı 
bir dönüşüm olarak sitüasyonist stratejilerinde gösterinin parçası olduğu düşünülebilir. Bu durum, sanat söyleminin düzeni içinde her türlü alternatif ya da sınır ötesinden gelen belirsizliğin kolaylıkla düzenlenişi olarak kabul bile edilebilir. Sanat sıkıntııının içerisinde değerlendirilebilinecek olan bu durum, her türlü üretimin şeyleşmeye ve yabancılaşamaya mahkûm olmasıdır. Dolayısıyla da sanat sahicilikten nasibini almamış olacaktır. Böyle bir yoksunlaştırıcı yorumun söylediği, görsel sanatların her türlü üretiminin çoktan angaje olmuş olduğudur ve sanatın ardında hiçbir şeyin kalmadığıdır. Sanatı sıfır noktasına çekmektedir. Bunun yerine önerilebilecek olanın ise kültür üzerine eleştirel bir yaklaşımın devam etmesi gerektiğidir. Kültürün üreticisi olarak sanatçının konumunun hâlâ geçerli olduğu hala sanatın eleştirel olabildiği ancak bu eleştiri diliyle kültürü sadece sanatın dönüştürebileceğinin beklenmesi ise açıkçası romantik bir tavırdır.

Buna karşılık sanatın angaje olma tehlikesi karşısında özerklik isteğinde olmasının kaçınılmaz olarak kendi meşruluğu için bir sıçrama tahtası bulması gerektiği sorununu hala düşünmek, bunun için ise sanat araçları üzerine sanatçının tavrını kurabilme özgürlüğünün devam ettiğini görmeye çalışmak en azından sanata dair kötümser tavrı azaltabilir. Ama en önemlisi kültürü var eden güçlerin sürekli göze getirilmesi gerektiğidir. Sanat da bunu yapmaya devam etmektedir.

Kültürü eleştirmeye, Adorno, Debord ve Baudrillard'ın garip bir şekilde ortak tutumları da olan, kitlenin eylemsiz olduğuyla başlamak yani karmaşık bir düzeneği göz ardı ederek sadece sanatçıyı 'kurtarıcı' ilan etmek yeterli görünmemektedir. Günümüz demokrasilerinde toplulukların ve bireylerin daha fazla katılımcı olmasını sağlamak, kitledeki belirsiz olanı göze getirmek, dillendirilmeyenlerin olduğunu düşünmek hala değerlidir. Belki de sanat, bu başkalıkları düşündükçe hala bir şeyleri dönüştürmeyi sürdürebilecektir. 


\section{Kaynakça}

Adorno, T. (2009). Kültür Endüstrisi Kültür Yönetimi. (Çev. N. Ülner, M. Tüzel, E. Gen ). Istanbul: Iletişim Yayınları.

Adorno, T., Horkheimer, M. (20 I0). Aydınlanmanın Diyalektiği. (Çev. N. Ülner, E. Öztarhan). istanbul: Kabalcı Yayınları.

Altuğ, T. (20/2). Son Bakışta Sanat. İstanbul: Yapı Kredi Yayınları.

Baudrillard, J. (2002). Simgesel Değiş Tokuş ve Ölüm . (Çev. O. Adanır). İstanbul: Boğaziçi Yayınları.

Baudrillard, J. (2004). Kötülüğün Şeffaflı̆ı.(Çev. I. Ergüden). İstanbul: Ayrıntı Yayınları.

Baudrillard, J. (20I0). Sanat Komplosu.(Çev. E. Gen). İstanbul: Iletişim Yayınları.

Best, S. ve Kellner, D. (1999). Postmodern Teori.(Çev. M. Küçük). İstanbul: Ayrıntı Yayınları.

Bilgin, K. (20/0). Baudrillard’ın Dili ya da Kuramın Krizi Üzerine Düşünceler. Armağan Öztürk (der.). Postyapısalcılık. Birinci Baskı. İstanbul: Phoenix Yayınları, s.279-323.

Borriaud, N. (2004). Postprodüksiyon. (Çev. N. Saybaşılı). İstanbul: Bağlam Yayınları.

Canjuers, P., Debord G. (20I I). Devrimci Programın Birliğini Tanımlamaya Doğru. A.

Artun (Editör).Sanat Manifestoları. İkinci Baskı. İstanbul. İletişim Yayınları, s.324-333.

Debord, G. (1996). Gösteri Toplumu. (Çev. A. Ekmekçi, O. Taşkent). İstanbul: Ayrıntı Yayınları.

Debord, G. (20I I). Politikada Veya Sanatta Yeni Eylem Biçimleri ve Sitüasyonistler. A. Artun (Editör). Sanat Manifestoları. İkinci Baskı. İstanbul. Iletişim Yayınları, s.335-344.

Dellaloğlu, B. (2003). Frankfurt Okulu'nda Sanat ve Toplum. İstanbul: Bağlam Yayınları.

Eagleton, T. (2003). Estetiğin İdeolojisi. (Çev.B. Gözkan, H. Hünler, T. Armaner, N. Ateş, A. Dost, E. Kılıç, E. Akman, N. Nur Domaniç, A. Çitil, B. Kıroğlu). Ankara: Doruk Yayınları.

Featherstone, M. (1996). Postmodernizm ve Tüketim Kültürü.(Çev. M. Küçük). İstanbul: Ayrıntı Yayınları.

Gottdiener, M. (2005). Postmodern Göstergeler. (Çev. A. Nur, E. Cengiz, H. Gür). Ankara: Imge Yayınları.

Jay, M. (1989). Diyalektik Imgelem.(Çev. S. Doğan). İstanbul: Kabalcı Yayınları.

Lotringer, S. (20I0). Sunuş: Sanat Korsanlığı. Sanat Komplosu. (Çev. E. Gen, I. Ergüden). Istanbul: İletişim Yayınları. 
Marcus, G. (1999). Ruj Lekesi Yirminci Yüzyılın Gizli Tarihi.(Çev. G. Koca). İstanbul: Ayrıntı Yayınları.

Perniola, M. (20I5). Sanat ve Gölgesi. (Çev. K. Atakay). İstanbul: Illetişim Yayınları.

Ray, G. (20/4). Kültür Endüstrisi ve Terör Yönetimi. A. Artun (Editör).Sanat Emeği. İstanbul: Iletişim Yayınları. s. 237-259.

Roberts, J. (20I3). Gündelik Hayatın Felsefesi. (Çev. E. Can Ercan). Ankara: Doruk Yayınları.

Sarup, M. (1997). Post-Yapısalcılık ve Postmodernizim Hakkında. (Çev. A. Güçlü). Ankara: Doruk Yayınları.

Slater, P. (1998). Frankfurt Okulu. (Çev. A. Özden). İstanbul: Kabalcı Yayınları.

Wark, M. (20/4). Kaldırım Taşlarının Altında Kumsal Var. (çev. Arda Çiletepe). İstanbul: Sel Yayınları.

Yibing, Z. (20I2). Derrida'nın Marx Hayaletleri, Baudrillard ve Debord'un Yeni Toplumu. (çev. D. Kızılçeç). Istanbul: Kalkedon Yayınları.

Zima, P. (2004). Modern Edebiyat Teorilerinin Felsefesi. (çev. M. Özsarı). İstanbul: Hece Yayınları. 